University of Nebraska - Lincoln

DigitalCommons@University of Nebraska - Lincoln

Roman L. Hruska U.S. Meat Animal Research

U.S. Department of Agriculture: Agricultural Center

Research Service, Lincoln, Nebraska

2002

\title{
Genetic Parameters of Reproductive Traits in Sheep
}

\author{
A. Rosati \\ Associazione Italiana Allevatori, rosati.a@aia.it \\ E. Mousa \\ Assiut University \\ L. D. Van Vleck \\ USDA-ARS \\ L. D. Young \\ USDA-ARS
}

Follow this and additional works at: https://digitalcommons.unl.edu/hruskareports

Rosati, A.; Mousa, E.; Van Vleck, L. D.; and Young, L. D., "Genetic Parameters of Reproductive Traits in Sheep" (2002). Roman L. Hruska U.S. Meat Animal Research Center. 250.

https://digitalcommons.unl.edu/hruskareports/250

This Article is brought to you for free and open access by the U.S. Department of Agriculture: Agricultural Research Service, Lincoln, Nebraska at DigitalCommons@University of Nebraska - Lincoln. It has been accepted for inclusion in Roman L. Hruska U.S. Meat Animal Research Center by an authorized administrator of DigitalCommons@University of Nebraska - Lincoln. 


\title{
Small Ruminant Research
}

ELSEVIER

\section{Genetic parameters of reproductive traits in sheep}

\author{
A. Rosati ${ }^{\text {a, }}$, E. Mousa ${ }^{\text {b }}$ L.D. Van Vleck ${ }^{\text {c,1 }}$, L.D. Young ${ }^{\text {c,2 }}$ \\ ${ }^{a}$ Associazione Italiana Allevatori, Via Nomentana 134, 00162 Rome, Italy \\ ${ }^{\mathrm{b}}$ Faculty of Agriculture, Assiut University, 71516 Assiut, Egypt \\ ${ }^{\mathrm{c}}$ Roman L. Hruska US Meat Animal Research Center, ARS, USDA, USA
}

Accepted 31 July 2001

\begin{abstract}
Reproductive traits from 7642 ewes were recorded from 1975 to 1983. The ewes were of five breeds (Dorset (D), Finnsheep (F), Rambouillet (R), Suffolk (S) and Targhee (T)) and two composite lines $[\mathrm{C} 1(1 / 2 \mathrm{~F}+1 / 4 \mathrm{R}+1 / 4 \mathrm{D})$ and $\mathrm{C} 2$ $(1 / 2 \mathrm{~F}+1 / 4 \mathrm{~S}+1 / 4 \mathrm{~T})]$. Genetic parameters were estimated for six basic and seven composite traits. The basic traits were conception rate (CR), total number of lamb born (NLB), number of lambs born alive (NLBA), number of lambs alive at weaning (NLAW), litter mean weight per lamb born (LMWLB) and litter mean weight per lamb weaned (LMWLW). The composite traits were ratio of lambs surviving to weaning relative to NLB (LSW = NLAW/NLB), number of lambs born per ewe exposed $(\mathrm{NLBEE}=\mathrm{CR} \times \mathrm{NLB}$ ), number of lambs weaned per ewe exposed (NLWEE $=\mathrm{CR} \times \mathrm{NLAW}$ ), total litter weight at birth (TLWB $=\mathrm{NLB} \times$ LMWLB), total litter weight at weaning (TLWW $=$ NLAW $\times$ LMWLW), total litter weight at birth per ewe exposed (TLWBEE $=\mathrm{CR} \times \mathrm{NLB} \times$ LMWLB) and total litter weight at weaning per ewe exposed $($ TLWWEE $=\mathrm{CR} \times$ NLAW $\times$ LMWLW). Year, age of ewe, breed of ewe, hormone treatment and season of breeding were used as fixed effects. Direct and maternal genetic effects, permanent environmental effects of ewe and mate of ewe were considered to be random effects. A derivative-free algorithm was used to obtain REML estimates of genetic and environmental parameters. Estimates of heritabilities for animal genetic and permanent environmental and maternal genetic effects were mainly small due to the typical high influence of environmental factors on reproductive traits and to non-normal distributions of traits. Mate of ewe effects were not important for any trait. Important genetic correlations were found between some traits. Some estimates of genetic correlations do not seem to have a biological explanation. Nevertheless, these estimates of genetic correlations among traits may provide a basis for deriving selection indexes for reproductive traits. (C) 2002 Published by Elsevier Science B.V.
\end{abstract}

Keywords: Heritability; Genetic correlations; Prolificacy

\section{Introduction}

One way to improve sheep production is by developing new breeds from a combination of older breeds.

\footnotetext{
* Corresponding author. Tel.: +39-6-8545-1304; fax: +39-6-8545-1322.

E-mail address: rosati.a@aia.it (A. Rosati).

${ }^{1}$ Lincoln, NE 68583-0908, USA.

${ }^{2}$ Clay Center, NE 68933-0166, USA.
}

Because of low reproductive rate, costs of maintaining dams as a proportion of total costs for meat production is greater in sheep than in swine or in poultry. Improvement of reproductive traits can have more economic impact than improving growth rate (Wang and Dickerson, 1991). Genetic improvement of growth rate and of reproductive traits are both important to increase lamb-meat production (Dickerson, 1978). Ewe productivity, measured as total lamb weight, could be achieved by selecting reproductive 
traits such as prolificacy, multiple birth and fecundity for the advantageous genetic correlations estimated by Hansen and Shreshta (1999). Growth rate has higher heritability than reproductive traits. Low heritability of reproductive traits is probably due to the greater proportional influence of environmental effects as well as little genetic variability for fertility, litter size, lamb survival and lambing frequency and other reproductive traits (Turner and Young, 1969). Hansen and Shreshta (1997) proved under conditions of artificial rearing, under a controlled environment that fertility, prolificacy and fecundity traits in sheep can be improved by selection for the large estimated heritability parameters. The data for the current research were available from the Sheep Maternal Breed Development Project at the Roman L. Hruska Meat Animal Research Center (MARC), Clay Center in Nebraska (Fogarty et al., 1984a). The flock used for this study originated in 1966 by crossing Dorset (D), Rambouillet $(\mathrm{R})$, Suffolk (S) and Targhee (T) breeds at MARC. Later, selected Finnsheep (F) rams and ewes were purchased. These breeds were selected for meat production (Dorset, Rambouillet, Suffolk and Targhee) and for reproductive traits (Finnsheep). Two composite dam lines were developed and are designated $\mathrm{C} 1=(1 / 2 \mathrm{~F}, 1 / 4 \mathrm{R}, 1 / 4 \mathrm{D})$ and $\mathrm{C} 2=(1 / 2 \mathrm{~F}, 1 / 4 \mathrm{~S}$, $1 / 4 \mathrm{~T})$. Composite lines were created to investigate the possibility of obtaining desirable combinations of breed effects and level of heterosis. Inter-se mating to create composite lines may result in recombination loss of advantageous non-allelic gene combinations but such a breeding system is easier to manage than most crossbreeding systems. The goal of this study, however, was to obtain estimates of heritability and genetic correlations that are necesssary to develop efficient selection strategies for improvement of reproduction.

\section{Materials and methods}

Data available were from a 9-year period, from 1975 through 1983, with 22,938 mating records observed. The numbers of records per breed group or category are listed in Table 1. Number of records of crossbred ewes distinct from $\mathrm{C} 1$ or $\mathrm{C} 2$ were included in the analyses. Part of the ewes were included in an accelerated lambing program. The ewes included in a
Table 1

Number of mating records and ewes by breed

\begin{tabular}{lcc}
\hline Breed & $\begin{array}{l}\text { Number of } \\
\text { mating records }\end{array}$ & $\begin{array}{c}\text { Number } \\
\text { of ewes }\end{array}$ \\
\hline Dorset & 4416 & 1438 \\
Finnsheep & 4015 & 920 \\
Rambouillet & 3376 & 1110 \\
Suffolk & 665 & 374 \\
Targhee & 1151 & 285 \\
Composite, C1 & 3657 & 1337 \\
Composite, C2 & 1314 & 607 \\
Other crossbreeds & 4344 & 1571 \\
Total & 22938 & 7642 \\
\hline
\end{tabular}

normal lambing program were exposed to rams in November but for those in an accelerated lambing management system, exposure to rams was in April, August and December. Approximately, two-third of the ewes were exposed to rams at intervals of 8 months and one-third at intervals of 12 months. Approximately, two-third of ewe lambs were first bred at 12 months of age and one-third at 16 months. This management resulted in most lambings in September (1088 observations), January (4109), March-April (4149) and May (4334). About one-half of the ewes managed for accelerated lambing received a hormone treatment. Ewes were kept for 32-38 days in mating pens with a single ram. About 1-2 weeks before lambing each ewe was transferred to a large pen inside a lambing barn. After lambing the ewe and the newly born lamb was placed in a $1.5 \mathrm{~m} \times 1.2 \mathrm{~m}$ pen for at least $24 \mathrm{~h}$, then grouped with other ewes and lambs in a nursery pen. Lambs remained with their dam until weaning between 5 and 10 weeks of age, depending on season and year. Excess lambs from multiple births were artificially reared, as were lambs that could not be reared by their own dam. Male lambs were not castrated. Culling policy was to keep all ewe lambs with the exception of animals having abnormalities and ewes that failed to lamb before 2 years of age. Ewes were generally culled at 7 years of age. Rams were kept until a male offspring was available for replacement. The mating scheme as described by Fogarty et al. (1984a) was planned to minimize cumulative inbreeding.

The traits analyzed can be assigned to two main categories: basic and composite traits (Table 2). Basic traits were conception rate (CR with measure of 1 or 0 , 
Table 2

Ranges and unadjusted means and standard deviations of basic and composite traits

\begin{tabular}{lllr}
\hline Traits acronyms & Trait & Range & Mean \pm S.D. \\
\hline CR & Conception rate & $0-1$ & $0.59 \pm 0.49$ \\
NLB & Number of lamb born & $1-7$ & $1.87 \pm 0.79$ \\
NLBA & Number of lambs born alive & $0-6$ & $1.68 \pm 0.80$ \\
NLAW & Number of lambs alive at weaning & $0-6$ & $1.48 \pm 0.87$ \\
LMWLB $(\mathrm{kg})$ & Litter mean weight per lamb born & $1.10-9.00$ & $4.11 \pm 1.20$ \\
LMWLW $(\mathrm{kg})$ & Litter mean weight per lamb weaned & $3.90-29.50$ & $13.51 \pm 4.05$ \\
NLBEE & Number of lambs born per ewe exposed & $0-7$ & $1.53 \pm 0.87$ \\
NLWEE & Number of lambs weaned per ewe exposed & $0-6$ & $1.38 \pm 0.80$ \\
TLWB $(\mathrm{kg})$ & Total litter weight at birth & $1.10-20.70$ & $7.20 \pm 2.50$ \\
TLWW $(\mathrm{kg})$ & Total litter weight at weaning & $0-68.10$ & $16.60 \pm 0.00$ \\
TLWBEE $(\mathrm{kg})$ & Total litter weight at birth per ewe exposed & $0-20.70$ & $5.57 \pm 3.43$ \\
TLWWEE $(\mathrm{kg})$ & Total litter weight at weaning per ewe exposed & $0-68.10$ & $17.89 \pm 10.50$ \\
LSW $(\%)$ & Lambs surviving to weaning & $0-100$ & $72.0 \pm 29.1$ \\
\hline
\end{tabular}

that is whether a ewe exposed to a ram did or did not lamb), total number of lambs born (NLB, the number of fully formed lambs born per ewe lambing), number of lambs born alive (NLBA, the number of lambs alive at 1 day of age), number of lambs alive at weaning (NLAW, the number of lambs alive at weaning, reared both by the ewe and in the nursery). Conception rate is a binary random variable and all other traits have discrete numerical observations. The other basic traits have continuous expression: litter mean weight per lamb born (LMWLB, i.e. the average weight of lambs at birth from the same parity) and litter mean weight per lamb weaned (LMWLW, the average weight of lambs at weaning from the same parity). Based on observations from basic traits, composite traits were calculated. The composite traits with discrete numerical observations were number of lambs born per ewe exposed for breeding (NLBEE: $\mathrm{CR} \times \mathrm{NLB}$ ) and number of lambs weaned per ewe exposed (NLWEE: $\mathrm{CR} \times \mathrm{NLAW}$ ). Composite traits with continuous expression were total litter weight at birth (TLWB), total litter weight at weaning (TLWW), total litter weight at birth per ewe exposed (TLWBEE: $\mathrm{CR} \times \mathrm{TLWB}$ ), total litter weight at weaning per ewe exposed (TLWWEE: CR $\times$ TLWW) and lamb survival at weaning (LSW, the fraction of lambs alive

Table 3

Fixed and random effects fitted in the final animal model for each trait analyzed

\begin{tabular}{|c|c|c|c|c|c|c|c|c|c|}
\hline \multirow[t]{2}{*}{ Trait } & \multicolumn{4}{|c|}{ Random effect } & \multicolumn{5}{|c|}{ Fixed effect } \\
\hline & $\begin{array}{l}\text { Direct } \\
\text { genetic }\end{array}$ & $\begin{array}{l}\text { Maternal } \\
\text { genetic }\end{array}$ & $\begin{array}{l}\text { Permanent } \\
\text { environment }\end{array}$ & Ewe-mate & $\begin{array}{l}\text { Breed } \\
\text { of ewe }\end{array}$ & $\begin{array}{l}\text { Year of } \\
\text { breeding }\end{array}$ & $\begin{array}{l}\text { Season of } \\
\text { breeding }\end{array}$ & $\begin{array}{l}\text { Age of } \\
\text { the ewe }\end{array}$ & $\begin{array}{l}\text { Hormone } \\
\text { treatment }\end{array}$ \\
\hline CR & $X$ & & $\mathrm{X}$ & & $\mathrm{X}$ & $X$ & $X$ & $X$ & $\mathrm{X}$ \\
\hline NLB & $\mathrm{X}$ & $\mathrm{X}$ & $\mathrm{X}$ & & $\mathrm{X}$ & $\mathrm{X}$ & $\mathrm{X}$ & $\mathrm{X}$ & $\mathrm{X}$ \\
\hline NLBA & $\mathrm{X}$ & $\mathrm{X}$ & $\mathrm{X}$ & & $X$ & $\mathrm{X}$ & $\mathrm{X}$ & $\mathrm{X}$ & \\
\hline NLAW & $X$ & $\mathrm{X}$ & & & $\mathrm{X}$ & & $X$ & $X$ & \\
\hline LMWLB (kg) & $\mathrm{X}$ & $\mathrm{X}$ & $\mathrm{X}$ & & $\mathrm{X}$ & & $\mathrm{X}$ & $\mathrm{X}$ & \\
\hline LMWLW (kg) & $\mathrm{X}$ & $\mathrm{X}$ & & & $\mathrm{X}$ & $\mathrm{X}$ & $\mathrm{X}$ & $\mathrm{X}$ & $\mathrm{X}$ \\
\hline NLBEE & $X$ & $X$ & $X$ & $X$ & $\mathrm{X}$ & $X$ & $X$ & $X$ & $\mathrm{X}$ \\
\hline NLWEE & $\mathrm{X}$ & & & & $\mathrm{X}$ & $\mathrm{X}$ & $\mathrm{X}$ & $\mathrm{X}$ & $\mathrm{X}$ \\
\hline TLWB (kg) & $\mathrm{X}$ & $X$ & $\mathrm{X}$ & $\mathrm{X}$ & $X$ & $X$ & $X$ & $X$ & \\
\hline TLWW (kg) & $X$ & $\mathrm{X}$ & $X$ & $\mathrm{X}$ & $\mathrm{X}$ & & $X$ & $X$ & \\
\hline TLWBEE (kg) & $X$ & $\mathrm{X}$ & $\mathrm{X}$ & & $X$ & $X$ & $X$ & $\mathrm{X}$ & $\mathrm{X}$ \\
\hline TLWWEE (kg) & $\mathrm{X}$ & $\mathrm{X}$ & $X$ & & $\mathrm{X}$ & $X$ & $X$ & $X$ & $\mathrm{X}$ \\
\hline LSW (\%) & $X$ & $\mathrm{X}$ & & & $\mathrm{X}$ & $X$ & $X$ & $X$ & \\
\hline
\end{tabular}


at weaning of the lambs that were fully formed at birth: NLAW/NLB).

Mixed model methodologies used to analyze all traits included fixed effects due to year, age, breed of the ewe, hormone treatment and season of breeding, and random effects due to animal direct and maternal genetic effects, permanent environment of the ewe and mate of ewe. Each trait was fitted to a different model. The choice of fixed effects to be considered was made after testing whether the effects were statistically significant with a linear fixed effects model analyzed with PROC GLM of SAS (SAS, 1985). Because of the biological meaning that effects can have some influence, were included in the final animal model irrespective of the level of significance with a model with only fixed effects. All random effects were included in the initial animal model. If the estimate of the proportion of the variability of the trait attributed to a random effect was equal to zero the random effect was not included in the final animal model. The final models used are shown in Table 3. Direct genetic effect is attributed to the ewe and maternal genetic effect is from the mother of the ewe. Most of the ewes had more than one lambing record and the average was almost two records per ewe varying by trait. Phenotypic and genetic correlations were estimated among all traits. To estimate both phenotypic and genetic correlations, the same models used to obtain variance component estimates were utilized assuming a covariance structure. The estimates were obtained with the MTDFREML software (Boldman et al., 1993).

\section{Results and discussion}

Estimates of direct and maternal heritabilities, direct-maternal genetic correlation and fractions of variance due to permanent environmental effects of the ewe and of ewe-mate, as well as phenotypic variances, for each trait are shown in Table 4. All estimates are in the range of those summarized (Fogarty, 1995).

\subsection{Heritability estimates}

Heritability estimate for direct genetic effect of conception rate (CR) was 0.06 . The low estimate may be due to the importance of random environ-
Table 4

Estimates of direct $\left(h^{2}\right)$ and maternal $\left(\mathrm{m}^{2}\right)$ heritability and directmaternal genetic correlation $\left(r_{\mathrm{am}}\right)$ and fractions of variance due to ewe-mate $\left(s^{2}\right)$ and permanent environmental $\left(c^{2}\right)$ effects and total phenotypic variance $\left(\sigma^{2}\right)$ for basic and composite traits

\begin{tabular}{llllllr}
\hline Traits & $h^{2}$ & $m^{2}$ & $r_{\mathrm{am}}$ & $s^{2}$ & $c^{2}$ & \multicolumn{1}{c}{$\sigma^{2}$} \\
\hline CR & 0.06 & - & - & - & 0.08 & 0.21 \\
NLB & 0.10 & 0.01 & 0.85 & - & 0.08 & 0.31 \\
NLBA & 0.05 & 0.01 & 0.27 & - & 0.07 & 0.38 \\
NLAW & 0.01 & 0.04 & 0.89 & - & - & 0.41 \\
LMWLB (kg) & 0.13 & 0.01 & 0.59 & - & 0.11 & 1.22 \\
LMWLW (kg) & 0.15 & 0.06 & -0.50 & - & - & 9.87 \\
NLBEE & 0.09 & 0.01 & 0.38 & 0.00 & 0.06 & 0.65 \\
NLWEE & 0.07 & - & - & - & - & 0.44 \\
TLWB (kg) & 0.40 & 0.34 & -0.23 & 0.00 & 0.08 & 4.01 \\
TLWW (kg) & 0.17 & 0.10 & 0.51 & 0.01 & 0.04 & 45.00 \\
TLWBEE (kg) & 0.13 & 0.09 & 0.31 & - & 0.10 & 6.25 \\
TLWWEE (kg) & 0.11 & 0.04 & 0.04 & - & 0.05 & 40.16 \\
LSW (\%) & 0.12 & 0.03 & 0.27 & - & - & 8.01 \\
\hline
\end{tabular}

mental effects on variability of the observations and due to the categorical expression of the trait (Falconer, 1989). On an assumed underlying normal continuous scale the estimate of heritability was 0.10 , when calculated according to Dempster and Lerner (1950). Because the heritability estimate is quite low, improvement of CR by selection would be difficult even though CR has great economical importance.

The estimated heritability for direct effects of number of lambs born (NLB) was 0.10 , and for maternal genetic effects was 0.01. Estimate of the genetic correlation between these effects was 0.85 . Relative variance due to permanent environmental effects of ewe was similar to direct heritability $(0.08)$ while the variance of ewe-mate effects was negligible (0.01). The results indicate little evidence of maternal genetic effects on NLB.

Small estimates of genetic variances were found; estimates of heritability for direct and maternal genetic effects of number of lambs born alive (NLBA) were 0.05 and 0.01 , respectively and fraction of variance due to permanent environmental effects was 0.07 . Estimate of genetic variance due to ewe-mate was 0.01 . The difference in estimate of heritability for direct genetic effects compared to the estimate for number of lambs born probably is due to the environmental influences, e.g. neo-natal disease, on the mortality of lambs at the first day of life and of lambs born dead. 
The estimates of heritability were quite low for both direct and maternal effects of number of lambs alive at weaning (NLAW) 0.01 and 0.04 , respectively. The estimate of genetic correlation between the direct and maternal effects was 0.89 which cannot be considered important due to the low estimates of genetic variances for both effects. The influence of direct effects, i.e. those associated with the ewes, was expected to be small because it was not known which lambs were artificially fed in the nursery and which ones by their dam.

The heritability estimate of litter mean weight per lamb born (LMWLB) was 0.13 for direct and 0.01 for maternal genetic effects. The estimate of the genetic correlation between them was 0.59 . A preliminary model with ewe-mate as an uncorrelated random effect was tried, but the portion of the variability of the trait attributed to the ewe-mate was zero. The fraction of variance due to permanent environmental estimates for LMWLB was about the same of direct heritability, 0.11 .

The estimates of heritability of litter mean weight per lamb weaned (LMWLW) were 0.15 and 0.06 , respectively for direct and maternal effects with negative genetic correlation, -0.50 between them. In a preliminary animal model permanent environmental effects were associated with small ratio of variance to total variance and therefore was not included in the final animal model. Selection for LMWLW will result in heavier lambs at weaning, but the total productivity of the ewe is the total kilogram of lamb produced at weaning. Litter mean weight per lamb born can be used for selection to have lambs that will survive to weaning, because there is a high phenotypic correlation between weight at birth and survival (Fogarty et al., 1984b).

The distribution of composite traits are categorical and similar to NLB with the exception of having a large number of zero observations. Estimate of the variance for ewe-mate effect was small. Estimated heritability for the direct genetic effect of number of lambs born per ewe exposed (NLBEE) was 0.09. Estimates of variance due to permanent environmental effects were generally lower for composite traits than for basic traits. For NLBEE the fraction of variance due to permanent environmental effects was 0.06 .

As for NLBEE, the basic traits forming NLWEE are conditional on each other, i.e. CR equal to 1 , is needed to have observations different from zero for NLAW. The portion of variability attributed to the direct genetic effect was small, heritability of number of lambs weaned per ewe exposed (NLWEE) was 0.07. The estimate of direct heritability for NLWEE was lower than for NLBEE probably because the loss of lambs from birth to weaning is more related to environmental effects and to genotypes of lambs than to the genotypes of the ewes. The number of lambs exceeding two or more weaker lambs were artificially reared in a nursery which may have been the reason that the estimate of permanent environmental variance was close to zero. Thus, permanent environmental and maternal genetic effects were not included in the final animal model.

Total litter weight at birth (TLWB) is a combination of LMWLB and NLB and measures the capacity of the ewe to produce lamb weight at birth without considering the number of lambs born. Observations of the trait are continuous and can be considered approximately normally distributed although skewed to the right. The heritability estimates of TLWB were 0.40 and 0.34 for direct and maternal effects, respectively. The genetic correlation between the direct and maternal genetic effects was -0.23 . The large estimates of heritability seem to offer the possibility to select for TLWB. Selection for productivity can also be applied through TLWB because of the large genetic correlation estimates that TLWB has with other productive traits (Table 5). Selection intensity could be larger if out-of-season breeding were successful, in fact generation interval might be reduced for observations of TLWB are obtained at birth. Therefore, genetic trend can be, when generation intervals are reduced larger.

Heritability estimates of total litter weight at weaning (TLWW) were 0.17 and 0.10 for direct and maternal genetic effects, respectively. Heritability estimate of maternal genetic effects was lower than for TLWB probably because the model could not consider whether the lambs were artificially or naturally nursed and because the ewe effect probably diminished from birth to weaning. Selecting for this trait would be more difficult than for TLWB because of lower heritability estimates. The estimated fraction of variance due to permanent environmental effects is about half of the estimate for the same trait expressed at birth, i.e. TLWB. Total litter weight at weaning can 
Table 5

Estimate of genetic (above diagonal) and environmental (below diagonal) correlations

\begin{tabular}{lrrrrrrrrrrrrr}
\hline Traits & CR & NLB & NLBA & NLAW & NLBEE & NLWEE & LSW & LMWLB & LMWLW & TLWB & TLWW & TLWBEE & TLWWEE \\
\hline CR & - & 0.71 & 0.65 & 0.42 & 0.79 & 0.41 & 0.08 & 0.32 & 0.15 & 0.29 & 0.32 & 0.38 & 0.19 \\
NLB & 0.80 & - & 0.91 & 0.13 & 0.86 & 0.42 & -0.15 & -0.24 & 0.05 & 0.75 & 0.18 & 0.27 & 0.12 \\
NLBA & 0.81 & 0.85 & - & 0.52 & 0.81 & 0.21 & -0.08 & -0.19 & -0.32 & 0.60 & 0.51 & 0.18 & 0.14 \\
NLAW & 0.27 & -0.18 & 0.12 & - & 0.00 & -0.04 & 0.71 & -0.01 & 0.02 & 0.12 & 0.16 & 0.04 & 0.10 \\
NLBEE & 0.52 & 0.38 & 0.61 & -0.11 & - & 0.29 & -0.16 & -0.16 & -0.06 & 0.33 & 0.16 & 0.41 & 0.42 \\
NLWEE & 0.27 & -0.05 & -0.08 & 0.49 & 0.00 & - & 0.28 & -0.08 & -0.16 & 0.06 & 0.16 & 0.01 & 0.06 \\
LSW & -0.01 & 0.04 & -0.42 & 0.42 & -0.09 & 0.38 & - & 0.40 & 0.52 & 0.09 & 0.14 & -0.08 & 0.04 \\
LMWLB & 0.49 & 0.45 & -0.31 & -0.31 & 0.10 & 0.08 & 0.02 & - & 0.33 & -0.21 & -0.03 & -0.12 & 0.09 \\
LMWLW & 0.17 & -0.14 & -0.08 & -0.23 & 0.06 & 0.20 & 0.59 & 0.48 & - & 0.09 & -0.07 & 0.13 & 0.02 \\
TLWB & 0.51 & 0.47 & -0.20 & 0.16 & 0.25 & 0.09 & 0.74 & 0.26 & 0.16 & - & 0.15 & 0.88 & -0.03 \\
TLWW & 0.31 & 0.02 & -0.24 & 0.85 & -0.03 & 0.65 & 0.92 & 0.01 & 0.36 & 0.41 & - & 0.04 & 0.09 \\
TLWBEE & 0.52 & 0.17 & 0.40 & 0.03 & 0.08 & 0.00 & -0.22 & -0.06 & 0.09 & 0.65 & -0.25 & - & 0.46 \\
TLWWEE & 0.55 & 0.19 & 0.51 & 0.50 & 0.08 & 0.25 & 0.34 & -0.13 & 0.14 & 0.31 & 0.50 & 0.05 & - \\
\hline
\end{tabular}

be considered a primary trait for selection because it measures the overall productivity of the ewe in terms of weights of lamb produced per parity, but TLWW does not take into account $\mathrm{CR}$.

Total litter weight at birth per ewe exposed (TLWBEE) is the combination of CR, NLB and LMWLB. The trait measures the ability of the ewe to produce lamb weight at birth after exposure to the ram. The distribution is conditioned by the distributions of the basic traits; CR was binomially distributed, NLB was categorical and LMWLB was continuous and skewed to the right. The heritability estimate for direct genetic effects of TLWBEE was 0.13 . Estimates of variance components due to ewemate and maternal genetic effects were close to zero. Three main traits are involved when selection is possible: conception rate, number of lambs at birth and weight of all lambs. To select for TLWBEE may be desirable, even if the heritability of the direct genetic effect is not large because of the large genetic correlation between TLWBEE and overall productive traits, as TLWWEE. Observations on TLWBEE have taken some weeks in advance of observation on TLWWEE. This time period can be important for making breeding decisions, because with typical seasonal breeding activity of sheep, saving a few weeks may advance selection by one breeding season.

Total litter weight weaned per ewe exposed (TLWWEE) expresses the ability of the ewe to produce lamb weight at weaning given exposure to the ram and is a combination of CR, NLAW and LMWLW. The range observed was large, between 0 and $68.1 \mathrm{~kg}$, with $17.89 \mathrm{~kg}$ on the average and large variability with standard deviation of $10.5 \mathrm{~kg}$. Only $5 \%$ of TLWWEE were more than $30 \mathrm{~kg}$. Heritability estimates of TLWWEE were 0.11 and 0.04 for direct and maternal effects, respectively with near zero estimate of genetic correlation between them of 0.04 Ewe-mate as an uncorrelated effect was found not to be important. As for TLWB and TLWW, the estimated fraction of variance due to permanent environmental effects for TLWWEE was about half of that for the same trait observed at birth, i.e. TLWBEE. The trait has a low heritability estimate, possibly partly due to the unusual distribution of the trait and partly due to the number of possible environmental effects. The TLWWEE could be considered for selection purposes because it measures a total productivity of the ewe for lamb-meat production for a breeding year.

Lamb survival at weaning (LSW) is an inverse ratio of number of lambs born and lambs per litter alive at weaning, i.e. is a measure of the ability of the ewe to produce lambs able to survive from birth to weaning. In the present study, however, it was not possible to identify lambs reared artificially or with their dam. The heritability estimates of LSW were quite low for both effects, 0.12 and 0.03 for direct and maternal genetic effects, respectively.

\subsection{Correlation estimates}

Estimates of correlations are shown on Table 5. Some of the traits are measured subsequent to others. Composite traits are combinations of other measurable 
traits, so that high genetic correlations are expected with the component traits. The CR seems to be highly related with all other traits, with the exception of LSW, probably because all the other traits have measurements different from zero, only if conception is successful. The smaller correlations between CR and traits observed at weaning depend on the higher probability, with respect to traits observed at birth, of having zero observations independent of the CR. Because of the low estimate of heritability, selection for CR may not be desirable. Ewes not able to lamb by 2 year of age and at two successive possible lambing times were culled which could influence the estimate of heritability of CR and therefore also estimates of genetic correlations. The NLB has high genetic correlations with NLBA and with NLBEE, because NLBA is measured 1 day after NLB and NLBEE is NLB measured for all exposed ewes, regardless the outcome of observations of CR. When number of lambs in a litter at birth is large the weight of litter tends to increase, for the same reason a genotype giving a large number of lambs at birth would tend to give a large TLWB. A negative estimate of genetic correlation of NLB with LMWLB was also expected because a greater number of lambs in the litter would be associated with smaller weights of each lamb. Because of the low estimates of genetic variances of many traits most of the variation in those traits is due to random environmental variability. The large difference between the genetic and environmental correlations between NLB and LMWLB show that both genetic and environmental sources of variation may have different physiological paths to influence the characters. The goal of selecting for NLB is to increase the number of lambs born. Using NLBA instead might result in better selection decisions because it considers the ability of the ewes to produce viable lambs. The low heritability of NLBA, however, and the high genetic correlation between NLB and NLBA suggests that selection may be more useful with NLB than with NLBA.

For example, the expected correlated response in NLBA resulting from selecting for NLB would be $i_{\mathrm{NLB}} h_{\mathrm{NLB}} r_{\mathrm{g}}=i_{\mathrm{NLB}} \times 0.32 \times 0.91=0.29 \times i_{\mathrm{NLB}}$, while the expected direct response expected from selecting directly for NLBA would be $i_{\mathrm{NLBA}} h_{\mathrm{NLBA}}$ $=0.22 \times i_{\mathrm{NLBA}}$, where $i$ is the factor for intensity of selection, $h$ is the square root of heritability (or the accuracy of individual selection) and $r_{\mathrm{g}}$ is the genetic correlation between traits. Intensity of selection applied can be considered to be similar for direct and indirect solution. The genetic correlation estimated between NLB and NLBA, however, probably has a large sampling error mainly because of the small estimates of the heritabilities. In the approximation of standard error for estimates of genetic correlation as explained by Robertson (1959) both estimates of heritability are in the denominator. Thus, because NLB and NLBA both have small estimates of heritability, the standard error may be quite large. Estimated heritability for direct effect of NLBA is about half that for NLB, which may be due to environmental effects affecting neo-natal mortality of lambs or simply may be due to sampling variance.

Other traits with large positive genetic correlations with NLBA are NLAW, NLBEE, TLWW and TLWB. For NLBEE the main reason for a positive genetic correlation is because NLBEE is a composite trait of CR and NLBA. Large estimates of genetic and environmental correlations between NLAW and LSW were found, but the heritability estimate of NLAW was negligible, 0.01 , to consider any of the estimates of genetic correlations with NLAW to be important. Nevertheless, some of the environmental correlations could be considered. The environmental correlations were large for NLAW with NLWEE, TLWWEE, LSW and especially with TLWW where the estimate was 0.85 showing that environment effects have the same mechanism of influence for most of the traits observed at weaning.

The LMWLB had negative but small genetic correlation estimates with both NLB and NLBA showing that genotypes producing low number of lambs (low NLB and NLBA) also produce heavy lambs (large LMWLB). This result agrees with patterns for breed means: Finnsheep have a large number of lambs which are not heavy. The opposite is the case for Targhee. The environmental correlation estimate between LMWLB and NLB indicates that favorable temporary environmental effects tend to produce both many lambs and heavy lambs, while with unfavorable temporary environmental effects both small litter size and lighter lambs are expected. Estimates of genetic correlations between LMWLW and the other traits were quite small with the exception of with NLBA, LMWLB and LSW. The first of those is negative as 
between NLBA and LMWLB and probably for the same reasons. Positive estimates of genetic correlations for LMWLW with LMWLB and with LSW are because LSW is a composite trait influenced by LMWLW. The LMWLB and LMWLW are traits determined partly by the same genes.

The NLBEE had large and positive genetic correlation estimates with CR and NLB, the observable traits that form NLBEE, and as expected with NLBA, TLWB and TLWBEE. Less expected was the large estimate of correlation with TLWWEE, though pleiotropic effects between these traits can be assumed. Selecting for NLBEE or for NLWEE would be slow due to small estimates of heritability. Nevertheless, of interest is that all genetic correlation estimates for NLWEE with the same traits already considered for NLBEE were smaller, probably because all traits are associated with the ewes. Birth traits are more related to the ewe than weaning traits, when a large influence of lamb genotype is present. The genetic correlation between NLBEE and NLWEE was 0.29, while the environmental correlation was zero. The estimate of phenotypic covariance was strongly influenced by the estimate of genetic covariance even though heritabilities for both traits were small.

The estimate of the genetic correlation between TLWW and TLWB was small, 0.15 . This result suggests that even if only a few genes are responsible for both traits, genes resulting in heavy litter weight at birth, through number of lambs and weight of each, are not responsible for genes affecting milk production or more general maternal care. Nevertheless, lamb survival, that is certainly correlated with weight of each single lamb, is meaningful for genetic correlation between TLWW and TLWB. Other factors, not considered here, can influence the estimates of genetic correlation between TLWW and TLWB: lamb's own genotype and artificial nursing for some lambs. Observations for both TLWB and TLWW are influenced by categorical expression of number of lambs but TLWW has little chance to be highly correlated with TLWB. In fact, when TLWB is large it becomes more difficult for the ewe to wean all lambs as litter size at birth increases. The TLWBEE has smaller genetic correlation estimates with TLWB and with TLWW than correlations between them. The estimate of genetic correlation of TLWBEE with CR was higher than between TLWB and CR. Selecting for TLWBEE can be possible even with heritability of only 0.13 . Such selection would improve the ability of ewes to produce greater total weight of lambs at birth. Usually management systems for sheep-meat have lambs suckling their dam, so it is favorable to select ewes for production of kilograms of lamb at weaning. The trait furnishing a good measure of total productivity of the ewe is TLWWEE. This trait measures the ability of a ewe to have good CR, large average number of lambs produced and with considerable weight for each lamb. Unfortunately, heritability for this trait was quite low, 0.11 , but genetic correlations with almost all traits were negligible with the exception of NLBEE and CR that both contribute to the composite character. Large estimates of environmental correlations were found between TLWWEE and traits measured at weaning. The LSW has a heritability estimate similar to TLWWEE and favorable genetic correlations with traits measuring weaning weight and number of lambs alive at weaning. The LSW measures the combination and the interaction of ewe maternal care and lamb ability to survive during suckling time. Ewes pass to lambs part of the genes that influence the ability to survive from birth to weaning. The same ewe has genes influencing maternal care, that are extremely important for the lamb to survive. Thus, selecting for LSW furnishes the potential to select for maternal care and for ability to survive from birth to weaning. The selection goals for the sheep-meat industry are to have a large number of heavy lambs at weaning. To reach this goal a selection index can be applied. The index could include fertility traits such as CR and NLB; survival traits such as LSW; and weight traits at weaning such as TLWW.

\section{General consideration}

Estimates of variances due to animal direct genetic effects were estimated jointly with variances of other effects: maternal, ewe-mate and animal permanent environmental. Maternal effects were found to be important only for litter weight traits which is surprising because maternal effects in this model were due to the dam of the ewe which would seem to have little influence on lambing production of the offspring except that the maternal environment provided by 
the mother could influence the ewe's body weight and, in turn, litter weight.

Heritability estimates were quite small for almost all traits. Only for litter weight traits larger heritability estimates were found. For some traits, such as CR, the small estimates may also be due to binomial measurement. Heritability estimates may also be influenced by other factors not considered in the model used. The influence of ewe-mate considered as an uncorrelated random effect on ewe productivity was negligible for all traits even for litter weight traits. Genetic correlations among reproductive and prolificacy traits were generally large because they are conditionally distributed. Other interesting estimates of genetic correlations were with birth weight traits and with weaning weight traits.

Overall ewe productivity is TLWEE which is a composite trait formed by the basic traits of CR, NLBA, LSW, LMWW. Selecting for TLWWEE can be possible without knowing the phenotypic and genetic variability of the basic traits or the covariances among them. The alternative is to assign economic values for all direct traits. This alternative is not simple and may not be accurate due to errors in estimating heritabilities and genetic correlations. Parameter estimates also may not be the same for different breeding systems and for different locations. Expected response due to indirect selection for a trait also can be calculated, i.e. expected response in one trait when selection is applied to another trait. For example, estimates from this study suggest that selection for LMWLB will improve LMWLW $44.7 \%$ as much as selection directly on LMWLW.

Genetic correlations are strongly influenced by gene frequencies and because selection changes the frequencies, genetic correlations can change after a few generations of selection (Bohren et al., 1969). Genetic correlations often have large sampling errors, especially when heritability estimates are low (e.g. Robertson, 1959; Van Vleck and Henderson, 1961); thus there can be uncertainty about calculation of expected correlated responses.

Estimates of genetic correlations suggest that both NLBA and NLAW have a strong genetic association respectively with litter weight at birth and at weaning. Environmental conditions are not the same for different lambings of the same ewe because different numbers of lambs present at birth or at weaning create different environmental conditions that may influence weight at birth and at weaning. Ewes maternal influence is not the same when the number of lambs change, for instance available milk for each lamb is lower when number of lambs in the litter is larger. On the average, the mean weight of every lamb is smaller when the number of lambs is larger, but there is large variability among ewes.

Variability of some composite traits, such as NLWEE and TLWWEE, is strongly influenced by other basic or composite traits, such as CR, NLAW and NLB (Fogarty et al., 1985). Variability due to CR, NLB and NLAW may have a large influence on other traits when they are expressed in poor management. When environment is improved then variability of CR, NLB and NLAW may become less and their influence on composite traits for final productivity may also be less. Consequently assigning economic weights to produce a general selection index can be misleading when management conditions are not constant.

Selection based on dam's performance is not concurrent to selection based on traits expressed in lambs. Using observations on lamb productivity means using records on both sexes for selection and also reduces generation interval. Maternal effects, considered as ewe maternal ability, can be estimated from observations on individual lambs. Ewes can also be indexed for maternal ability. Such indexes need to be developed if selection to improve maternal ability is considered in the population. Use of individual lamb performance would make estimation of genetic values more difficult for fertility traits which are economically the most important traits to select (Wang and Dickerson, 1991). Use of CR of ewe to select for NLB or NLBA could be less costly because measurements can be easily done when pregnancy test becomes possible, that is some weeks before lambing. The decrease in possible genetic gain in one trait that occurs when another trait is selected also must be considered. Genetic responses for CR and NLB are limited due to the finite upper limit especially for CR. With good management, selection for CR and NLB could result in only limited gains. On the other hand, response to selection for all other traits is influenced by reproductive rate, because low number of lambs born and low CR rate would limit selection intensity and would increase generation interval. 


\section{Conclusion}

Estimates of genetic variances and heritabilities necessary for genetic evaluation of sheep and for choosing the best selection schemes were obtained. Economic weights for traits can be determined to build a advantageous overall selection index. Then the estimates of genetic correlations among the traits and their heritabilities can be used to create an overall index. Fertility traits are economically important and though found to have small genetic variances must be included in the overall index. Improving fertility traits may enhance selection because the number of animals available will be larger than with low reproductive performance.

\section{References}

Bohren, B.B., Hill, W.G., Robertson, A., 1969. Some observations on asymmetrical correlated responses. Genet. Res. 7, 44 57.

Boldman, K.G., Kriese, L.A., Van Vleck, L.D., Kachman, S. D., 1993. A manual for use of MTDFREML: a set of program to obtain estimates of variances and covariances. ARS, USDA, USMARC, Clay Center, NE.

Dempster, E.R., Lerner, I.M., 1950. Heritability of threshold characters. Genetics 35, 212-236.

Dickerson, G.E., 1978. Animal size and efficiency: basic concepts. Anim. Prod. 27, 367.
Falconer, D.S., 1989. Introduction to quantitative genetics, 3rd Edition. Wiley, New York.

Fogarty, N.M., 1995. Genetic parameters for live weight, fat and muscle measurements, wool production and reproduction in sheep: a review. Anim. Breed. Abstr. 63, 101-144.

Fogarty, N.M., Dickerson, G.E., Young, L.D., 1984a. Lamb production and its components in pure breeds and composite lines. I. Seasonal and other environment effects. J. Anim. Sci. 58, 285-300.

Fogarty, N.M., Dickerson, G.E., Young, L.D., 1984b. Lamb production and its components in pure breeds and composite lines. II. Breed effects and heterosis. J. Anim. Sci. 58, 301.

Fogarty, N.M., Dickerson, G.E., Young, L.D., 1985. Lamb production and its components in pure breeds and composite lines. III. Genetic parameters. J. Anim. Sci. 60, 40-57.

Hansen, C., Shreshta, J.N.B., 1997. Heritability and repeatability estimates for ewe productivity traits of three breeds under 8 months breeding cycles and artificial rearing of lambs. Small Rumin Res. 24, 185-194.

Hansen, C., Shreshta, J.N.B., 1999. Estimates of genetic and phenotypic correlations for ewe productivity traits of three breeds under 8 months breeding cycles and artificial rearing of lambs. Small Rumin Res. 32, 1-11.

Robertson, A., 1959. The sampling variance of the genetic correlation coefficient. Biometrics 15, 469-485.

SAS ${ }^{\circledR}$ User's Guide: Statistics, Version 5th Edition. SAS Institute Inc., Cary, NC.

Turner, H.N., Young, S.Y., 1969. Quantitative genetics in sheep breeding. MacMillan, Melbourne, Australia.

Van Vleck, L.D., Henderson, C.R., 1961. Empirical sampling estimates of genetic correlations. Biometrics 17, 359-371.

Wang, C.T., Dickerson, G.E., 1991. Simulated effects of reproductive performance on life-cycle efficiency of lamb and wool production at three lambing intervals. J. Anim. Sci. 69, 4338-4347. 